$2001-2$ to $16 \%$ in $2005-6, p<0.001$ ) for children at all treatment steps including those prescribed short acting beta agonist only. Only 27 children were prescribed LABA without concurrent ICS and of the 710 children prescribed LABA/ICS combination, 176 (25\%) had not been prescribed ICS in the previous year.

Conclusions Revisions of the BTS/SIGN guidelines do modify prescribing practice in children. The greater use of LABA, LTRA and reduction in ICS dose has been accompanied by a greater use of OCS that may reflect poorer control of acute episodes or a lower threshold and greater confidence by prescribers in the use of OCS.

Abstract P74 Table 1 Change (\%) in asthma medications prescribing by age group

\begin{tabular}{lccl}
\hline & 2001-2002 & 2005-2006 & p-value \\
\hline LABA & & & \\
$0-4$ & 2.5 & 3.8 & NS \\
$5-11$ & 10.1 & 16.8 & $<0.001$ \\
$12-18$ & 11.1 & 14.7 & $<0.001$ \\
& & & \\
LTRA & & & $<0.001$ \\
$0-4$ & 2.8 & 8.4 & $<0.001$ \\
$5-11$ & 3.3 & 7.3 & NS \\
$12-18$ & 2.8 & 3.8 & \\
& & & $<0.001$ \\
0 OCS & & 16.0 & $<0.01$ \\
$0-4$ & 9.0 & 9.6 & NS \\
$5-11$ & 6.7 & 6.5 & \\
$12-18$ & 5.3 & &
\end{tabular}

\section{P75 CLINICAL PREDICTORS OF CONTINUOUS POSITIVE AIRWAY PRESSURE REQUIREMENT IN BRONCHIOLITIS}

doi:10.1136/thx.2010.150979.26

J Evans, M Marlais, E Abrahamson. Department of Paediatric Emergency Medicine, Chelsea and Westminster Hospital, London, UK

Background Bronchiolitis is the commonest respiratory viral illness in infants with the potential for significant morbidity. There is growing evidence for the use of continuous positive airway pressure (CPAP) non-invasive ventilation in the most seriously affected of these children. Despite the increasing literature regarding the use of CPAP there are currently no studies which identify clinical predictors of requirement for CPAP using the UK bronchiolitis age limit of 12 months, leaving the decision to clinical judgement alone.

Objective To identify clinical factors in infants with bronchiolitis at the time of presentation to the emergency department, which might predict a requirement for CPAP following admission.

Methods Retrospective review of paediatric emergency department case notes was conducted on all bronchiolitis admissions to one tertiary paediatric emergency department in a 12 -month period (April 2009-March 2010). Inclusion criteria consisted of a clinical diagnosis of bronchiolitis in those 12 months of age or under. Potential clinical predictors were identified through an extensive literature review. Data extraction of these predetermined potential clinical predictors was carried out and recorded for each case. Logistic regression was then conducted for each variable to identify statistically significant independent predictors of CPAP requirment. Results During the study period 163 infants were admitted with acute bronchiolitis. Of the 163 infants admitted 28 (17\%) received CPAP. The most significant predictors of CPAP requirement in those admitted were as follows: lower oxygen saturation (mean $92.7 \%$ vs $97.1 \%, \mathrm{p}<0.001$ ), oxygen requirement in the emergency department $(89.3 \%$ vs $24.4 \%, p<0.001)$, lower weight at presentation (mean
$4221 \mathrm{~g}$ vs $6668 \mathrm{~g}, \mathrm{p}<0.001$ ), higher capillary blood gas $\mathrm{PaCO}_{2}$ (mean $8.32 \mathrm{kPa}$ vs $6.05 \mathrm{kPa}, \mathrm{p}<0.001)$ and higher capillary blood gas $\mathrm{HCO}_{3}$ (mean $30.5 \mathrm{mmol} / \mathrm{l}$ vs $26.5 \mathrm{mmol} / \mathrm{l}, \mathrm{p}<0.001$ ).

Conclusion We have identified a number of clinical variables which may be assessed within the emergency department, each independently predictive of CPAP requirement in those who are admitted with bronchiolitis. These findings are of particular importance as an aid to clinical assessment of bronchiolitis severity. They are also likely to have a useful role in logistical management decisions, allowing early planning for non-invasive ventilation.

\section{P76 GENERAL AND RESPIRATORY HEALTH OUTCOMES IN ADULT SURVIVORS OF BRONCHOPULMONARY DYSPLASIA: A SYSTEMATIC REVIEW}

doi:10.1136/thx.2010.150979.27

A Gough, D Spence, M A Linden, L McGarvey, H Halliday. Queen's University, Belfast, Northern Ireland

Introduction and objectives Bronchopulmonary dysplasia (BPD) is the most common form of chronic lung disease in infancy and the second most common after asthma in children. With the improved survival of extremely preterm infants the incidence of BPD has increased. Currently there is only limited information on the health of BPD survivors who have reached adulthood. The purpose of this systematic literature review was to examine current empirical research on adult survivors of BPD.

Methods Six electronic databases were searched between 1950 and February 2010 (Medline, PubMed, Embase, PsycINFO, Cumulative Index of Nursing and Allied Health Literature (CINAHL Plus) and Web of Knowledge. Studies were independently screened and were only included if they related to the assessment of outcome measures in adult survivors of BPD. From a total of 1453 search results, 14 eligible studies were included in the review. Data on methodological design and findings were extracted from each included study; in addition the methodological quality of each study was assessed using the Critical Appraisal Skills Programme (CASP) checklist.

Results 14 cohort studies met the review criteria. 12 scored highly on the CASP checklist, with a score $>10$ out of 12 . No study scored less than 7 . Nine studies included a control group and only four studies in total had a singular focus on BPD outcomes. Six controlled studies found differences between the groups on respiratory symptoms. 11 studies carried out lung function testing and found evidence of airflow obstruction. Of these, one study found no difference between preterm and controls. However, there were only seven adults who were born preterm with BPD in this study. Five studies in total examined radiographical outcomes, and all found evidence of abnormalities. Those with moderate-severe BPD were found to be most affected compared to mild BPD subjects.

Conclusions The effects of BPD on pulmonary function do not diminish over time. This may reflect issues related to means of testing, differing definitions and classification of $\mathrm{BPD}$, and the adaptation of individuals to their circumstances over time.

\section{P77 CHILDREN'S EXPOSURE TO AIRBORNE FINE PARTICULATE MATTER AT HOME AND ASTHMA OUTCOMES}

doi:10.1136/thx.2010.150979.28

K Woods, A Apsley, S Semple, S W Turner. University of Aberdeen, Aberdeen, UK

Objectives The relationship between indoor air exposure to fine particulate $\left(\mathrm{PM}_{2.5}\right)$ and asthma symptoms in children is uncertain. The aim of the present study was to relate $\mathrm{PM}_{2.5}$ exposure to indices of asthma severity and control. 